\title{
Development and validation of a simple and fast method for simultaneous determination of sunset yellow and azorubine in carbonated orange flavor soft drinks samples by high- performance liquid chromatography
}

\author{
Mohammad Faraji ${ }^{1}$, Gholamrezza Ghasempour ${ }^{1}$, Banafshe Nasiri Sahneh ${ }^{1}$, Rika \\ Javanshir ${ }^{1}$, Mina Alavi \\ ${ }^{l}$ Faculty of Food Industry and Agriculture, Department of Food science \& Technology, Standard Research \\ Institute (SRI), Karaj P.O. Box 31745-139, Iran
}

\begin{abstract}
An efficient method was developed for the simultaneous determination of sunset yellow and azorubine in carbonated orange flavor soft drink samples by high performance liquid chromatography (HPLC$U V$-Vis). Affecting parameters on separation and detection of the dyes were investigated and optimized. For these dyes good linearity $\left(0.25-50 \mathrm{mg} \mathrm{L}^{-1},>r^{2}=0.99\right)$ were obtained. Limits of detection for both of the dyes were $0.1 \mathrm{mg} \mathrm{L}^{-1}$. The recoveries of the dyes ranged from 92 to 102\%. Intra and inter-day precision expressed as relative standard deviation (RSD\%) at 5.0 and $50 \mathrm{mg} \mathrm{L}^{-1}$ levels less than $8.0 \%$ were also achieved. This method has been applied successfully in the determination of the sunset yellow and azorubine in soft drink samples. The average sunset yellow concentration of the 42 soft drink samples range between $20.6-60.2 \mathrm{mg} \mathrm{L}^{-1}$. Also, azorubine was found in the soft drink samples in the range of N.D-4.4 mg $L^{-1}$. There results confirmed that there are two different formulations in soft drink sample samples. Obtained results showed that levels of the sunset yellow individually or in combination with azorubine in all of the tested samples is lower than EU maximum permitted level ( $\left.100 \mathrm{mg} \mathrm{L}^{-1}\right)$.
\end{abstract}

Keywords: Synthetic dyes, High performance liquid chromatography, Sunset yellow, Azorubine, Carbonated orange flavor soft drinks.

\section{Introduction}

Carbonated soft drinks are very popular beverages. Although their regular intake has been associated with human health problems [1-3], carbonated soft drinks remain one of the most frequently consumed ready-todrink beverages in the world. They present particular characteristics such as high sugar content and acidity, and are available on the market in several flavors. In Iran, the most popular carbonated soft drinks are orange or cola-based.

Synthetic dyes are usually added to foodstuffs and soft drinks not only to improve appearance, colour and texture but also to maintain the natural colour during process or storage [4]. Compared to natural dyes, synthetic dyes show several advantages such as high stability to light, oxygen and $\mathrm{pH}$, colour uniformity, low microbiological contamination, relatively lower production costs, etc [5] .

Sunset yellow (SY, E-110) and azorubine (E-122) are two highly used synthetic dyes which are added to many food products [6]. The presence and content of these dyes must be controlled due to their potential harmfulness to human beings [7].

An extensive review on the genotoxicity of food, drug, and cosmetic azo dyes and other dyes had been presented in the literature [8]. The European Union [9] has issued comprehensive schemes that regulating the use of food colours and their allowed levels in all food products. The maximum level of SY, and azorubine dyes should not be more than $100 \mathrm{mg} \mathrm{L}^{-1}$ (individually or in combination) in nonalcoholic beverages with added juices and/or flavours [6]. Accordingly, monitoring of synthetic food dyes in high consumption products such as beverages becomes an essential task. Thus, it is necessary to develop accurate and reliable analytical methods for the confirmative determination of synthetic food dyes in soft drinks to ensure food safety and consumer health.

A large number of analytical methods for food colors have been proposed, such as thin layer chromatography (TLC) [10], voltammetry [11], polarography [12], spectrophotometry [13,14], capillary electrophoresis (CE) [15,16], ion chromatography [17], and high-performance liquid chromatography (HPLC) [18-24]. Voltammetry, polarography, and spectrophotometry are simple and rapid methods, however, they are not suitable for determining multiple food color mixtures in the food matrix. Therefore, HPLC is extensively used for determination of multiple food color mixtures in the food matrix. 
Usually in formulation of orange flavored soft drinks sunset yellow is used but in some formulation combination of sunset yellow and azorubine is also used in order to increase intensity of orange color. Therefore, the aim of this study was to develop and validate a fast, reliable, selective and economic HPLC method for routine analysis of sunset yellow and azorubine dyes in orange flavored soft drinks samples in food analysis laboratories.

\subsection{Chemicals and reagents}

\section{Material and methods}

HPLC-grade methanol was obtained from Merck Company (Darmstadt, Germany). Analytical grade ammonium acetate and acetic acid were purchased from Merck Company (Darmstadt, Germany). Water was purified using a Milli-Q Ultrapure water purification system (Millipore, Bedford, MA, USA). Azorubine and Sunset Yellow FCF (SY) were purchased from Sigma-aldrich (Steinheim, Germany). The structures, names and color index (C.I.) numbers of the dyes used in this study are shown in Fig. 1. All of the stock solutions (1000 mg $\left.\mathrm{L}^{-1}\right)$ were prepared in water. Working solutions $\left(20 \mathrm{mg} \mathrm{L}^{-1}\right)$ were prepared freshly mixing the stock solutions and diluting with water. Ammonium acetate buffer $\mathrm{pH}=6.7$ with concentration of $100 \mathrm{mM}$ was prepared by dissolving proper amount of salt in deionzed water by adjusting with dropwise addition of acetic acid followed by filtration.
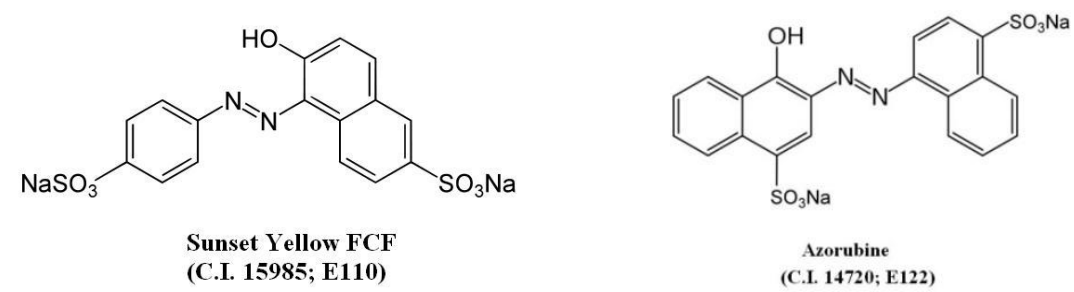

Fig. 1. Chemical structure, name, color index and Enumber of the dyes used.

\subsection{Apparatus}

The chromatographic analysis was carried out in a high-performance liquid chromatography from Knauer of Germany model EuroChrom consisting of a degasser, quaternary pump (model K1100), manual sample injector with $20 \mu \mathrm{L}$ loop size and UV detector (model K2600) was controlled by EZChrom software. The HPLC operating mode was gradient, the injection volume was $20 \mu \mathrm{L}$ and the column temperature was adjusted at room temperature. The chromatography column was a Supelcosil LC-18: $25 \mathrm{~cm} \times 4.6 \mathrm{~mm}, 5 \mu \mathrm{m}$ (Supelco, Bellefonte, PA, USA). Sample data collection was optimized to 8 min per sample with UV detection at wavelength of $500 \mathrm{~nm}$. Mobile phase used was combination of methanol and ammonium acetate buffer (100 $\mathrm{mM}) \mathrm{pH}=6.7(22: 78, \mathrm{v} / \mathrm{v} \%)$ in isocratic mode. The mobile phase was filtered through a $0.45 \mu \mathrm{m}$ pore size filter (Merck Millipore, Billerica, Massachusetts, USA) and degassed by vacuum prior to use. Moreover, the mobile phase flow rate was set to $1.0 \mathrm{~mL} \mathrm{~min}^{-1}$. All of the $\mathrm{pH}$ measurements were performed with a WTW Inolab $\mathrm{pH}$ meter (Weilheim, Germany).

\section{Results and Discussion}

\subsection{Choosing the best conditions for detection and separation of the dyes}

It is well known that the detection wavelength is one of the most important factors affecting the sensitivity of the method. So, in order to achieve the highest sensitivity in determination of the dyes, the detection of them must be done in their $\lambda_{\max }$. $\lambda_{\max }$ for SY and Az is reported $485 \mathrm{~nm}$ and $515 \mathrm{~nm}$, respectively. So, detection wavelength was evaluated in the rage of 485-515 $\mathrm{nm}$. Results showed that detection sensitivity is good for SY when $\lambda<500 \mathrm{~nm}$ specially $485 \mathrm{~nm}\left(\lambda_{\max }\right)$. On the other hand, detection sensitivity is good for Az when $\lambda>500 \mathrm{~nm}$ specially $515 \mathrm{~nm}\left(\lambda_{\max }\right)$. So, under this circumstance, detection wavelength of $500 \mathrm{~nm}$ was selected in order to obtain good sensitivity for both of the dyes.

Composition of mobile phase is key factor in resolution of chromatographic separation as same as run time of analysis. Mobile phases containing ammonium acetate buffer as buffering compounds are obviously recommended as the most suitable to assure the very good chromatographic separation of the sulphonated azo dyes [23]. Several different mobile phases were tested including methanol-acetate buffer (15:85), methanolacetate buffer (20:80), methanol-acetate buffer (22:78), methanol-acetate buffer (25:75), methanol-acetate buffer (30:70). Obtained results showed that in low percent of methanol (methanol-acetate buffer (15:85)), azorubine was eluted so late. On the other hand, in high percent of methanol (such as methanol-acetate buffer (30:70)), resolution of SY and Az are not good. So, by evaluating these results, the mobile phase of methanolacetate buffer (22:78) was selected because of suitable resolution, good peak shape and also short run time (10.0 
min). Under optimum condition, the retention times for SY (first peak) and Az (second peak) are about 3.5 and $8.5 \mathrm{~min}$, respectively.

\subsection{Analytical performance}

\subsubsection{Linear range}

The linearity for each compound was checked by analyzing mixed standard solutions of 11 different concentrations $\left(0.1,0.25,0.5,1,2,5,10,20,30,40\right.$, and $\left.50 \mathrm{mg} \mathrm{L}^{-1}\right)$. Table 1 shows the linear range found for each dyes and the regression coefficient obtained, expressed as $r^{2}$. As can be seen, a wide and convenient linear range was obtained for the dyes. Calibration curves of sunset yellow and azorubine are shown in Fig. 2.
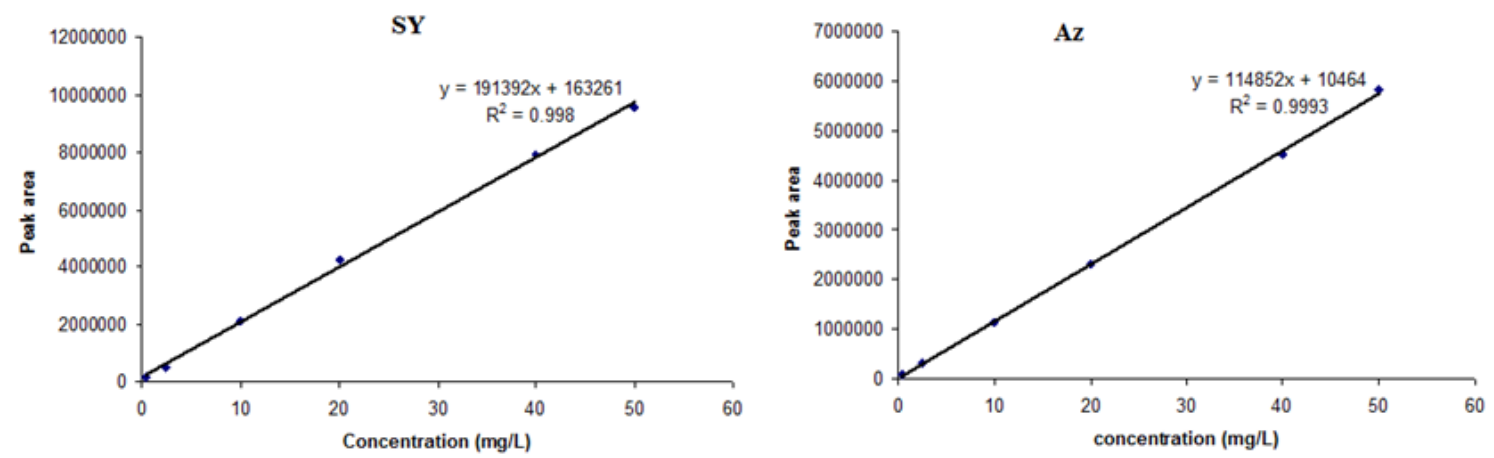

Fig. 2. Calibration curves of sunset yellow and azorubine

Table 1. Analytical characteristics of the HPLC method

\begin{tabular}{|c|c|c|c|c|c|c|c|c|c|c|}
\hline \multirow{3}{*}{ Dyes } & \multicolumn{6}{|c|}{ RSD\% } & \multirow{3}{*}{$\begin{array}{c}\text { LOQ } \\
(\mathrm{mg} / \mathrm{L})\end{array}$} & \multirow{3}{*}{$\begin{array}{c}\text { LOD } \\
(\mathrm{mg} / \mathrm{L})\end{array}$} & \multirow{3}{*}{$\begin{array}{c}\text { Linear Range } \\
(\mathrm{mg} / \mathrm{L})\end{array}$} & \multirow{3}{*}{$\mathbf{R}^{2}$} \\
\hline & \multicolumn{3}{|c|}{ Inter-days $(\mathrm{n}=6)$} & \multicolumn{3}{|c|}{ Intra-day $(n=6)$} & & & & \\
\hline & $0.5^{\mathrm{a}}$ & 5.0 & 50 & 0.5 & 5.0 & 50 & & & & \\
\hline SY & 8.3 & 7.3 & 5.4 & 5.5 & 3.9 & 2.8 & 0.25 & 0.1 & $0.25-50$ & 0.9980 \\
\hline$\overline{A z}$ & 6.5 & 6.8 & 4.7 & 4.8 & 5.2 & 3.5 & 0.25 & 0.1 & $0.25-50$ & 0.9993 \\
\hline
\end{tabular}

\subsubsection{Precision}

The method exhibited excellent precision, as shown in Table 1. Fortification/recovery experiments resulted in low intra day relative standard deviations (R.S.D.s) for the analytes ( $\mathrm{n}=6$, R.S.D.s $<8 \%$ ) at three different levels $\left(0.5,5,50 \mathrm{mg} \mathrm{L}^{-1}\right)$. A comparison of fortification/recovery experiments conducted on six different days $(\mathrm{n}=6)$ at three different levels $\left(0.5,5,50 \mathrm{mg} \mathrm{L}^{-1}\right)$ also displayed low inter-day R.S.D.s $(<9 \%)$, confirming the excellent reproducibility of the method. Moreover, inter-laboratory study was done. Results are summarized in Table 2. Obtained results showed that developed method is completely reproducible.

Table 2. inter-laboratory study results

\begin{tabular}{|c|c|c|c|c|c|c|}
\hline Laboratory ID & \multicolumn{2}{|c|}{ Sample code 1} & \multicolumn{2}{|c|}{ Sample code 2} & \multicolumn{2}{|c|}{ Sample code 3} \\
\hline Lab 2 & 56.1 & $<0.1$ & 25.4 & 2.3 & 46.9 & $<0.1$ \\
\hline Lab 4 & 52.9 & $<0.1$ & 24.3 & 2.9 & 45.1 & $<0.1$ \\
\hline Lab 5 & 56.0 & $<0.1$ & 25.1 & 2.7 & 46.0 & $<0.1$ \\
\hline & & & & cal Results & & \\
\hline SD & 2.5 & - & $0.7_{8}$ & $0.2_{6}$ & 1.2 & - \\
\hline RSD\% & 4.6 & - & 3.1 & 9.8 & 2.7 & - \\
\hline
\end{tabular}

\subsubsection{Detection and quantitation limits}

Detection limits were calculated by extracting diluted solutions of the analytes $(0.01,0.05,0.1$ and 0.2 $\left.\mathrm{mg} \mathrm{L}^{-1}\right)$. The criteria were selected according to IUPAC and ACS definition, as follows:

Detection limit (DL): $A_{s}-A_{b}=3 S_{b}$

Quantitation limit (QL): $A_{s}-A_{b}=10 S_{b}$

were $A_{s}$ is the average of sample signal (area); $A_{b}$ is the average of blank signal (area) and $S$ is the standard deviation of blank signal (area). The obtained limits of the method are presented in Table 1. 


\subsubsection{Accuracy}

Due to the lack of Certified Reference Materials, accuracy evaluation, in terms of percentage of recovery, was carried out on blank samples spiked with a known amount of analyte (level of $10 \mathrm{mg} \mathrm{L}^{-1}$ ). Data for these experiments are shown in Table 3. Good results were obtained, with average recoveries ranging from 92 to $102 \%$ and also between 92 and $101 \%$ for sunset yellow and azorubine, respectively. It is interesting to note that, samples did not require matrix matched calibration curves to compensate for difficulties in measuring peak area for the dyes at low concentration, making more rapid analysis possible.

Table 3. Results of food color recovery study

\begin{tabular}{|l|c|c|c|}
\hline Sample ID & $\mathbf{C}_{\text {added }}\left(\mathbf{m g ~ L}^{-1}\right)$ & \multicolumn{2}{|c|}{${ }^{\mathbf{a}}$ Recovery \% } \\
\cline { 3 - 4 } & & Sunset yellow & Azorubine \\
\hline Code 1 & 10.0 & 96 & 97 \\
\hline Code 2 & 10.0 & 92 & 101 \\
\hline Code 3 & 10.0 & 98 & 94 \\
\hline Code 4 & 10.0 & 102 & 95 \\
\hline Code 5 & 10.0 & 94 & 92 \\
\hline Code 6 & 10.0 & 98 & 97 \\
\hline Code 7 & 10.0 & 96 & 94 \\
\hline Code 8 & 10.0 & 93 & 99 \\
\hline Code 9 & 10.0 & 97 & 93 \\
\hline Code 10 & 10.0 & 99 & 96 \\
\hline
\end{tabular}

${ }^{a}$ RSD values for three replicate measurements for all of the tested samples were less than $10 \%$

\subsection{Application}

The validated method was applied to determine content of sunset yellow and azorubine in different soft drink samples collected locally and the results are summarized in Table 4. RSD values for three replicate measurements for all of the tested samples were less than 7.0\%. In the analysis of the samples, peak identification was based on the comparison between the retention times of standard compounds and was confirmed by spiking standards to the samples. Quantification was based on the external standard method using calibration curves fitted by linear regression analysis. Under the stated experimental conditions, baseline separation of the two dyes was achieved in less than $10 \mathrm{~min}$. A typical HPLC-UV-Vis chromatogram of a carbonated soft drink sample before (3a) and after spike (3b) $10 \mathrm{mg} \mathrm{L}^{-1}$ of the each dyes is shown in Fig. 3

The average sunset yellow concentration of the 42 soft drink samples range between 20.6- $60.2 \mathrm{mg} \mathrm{L}^{-1}$. Also, azorubine was found in the soft drink samples in the range of N.D-4.4 mg L-1. There results confirmed that there are two different formulations in soft drink sample samples. In some samples only sunset yellow has been used to produce orange color but some companies has been used combination of the both sunset yellow and azorubine in their formulation. Moreover, sum of the sunset yellow and azorubine concentration in the tested soft drink sample are in compliance with EU limit $\left(100 \mathrm{mg} \mathrm{L}^{-1}\right)$.
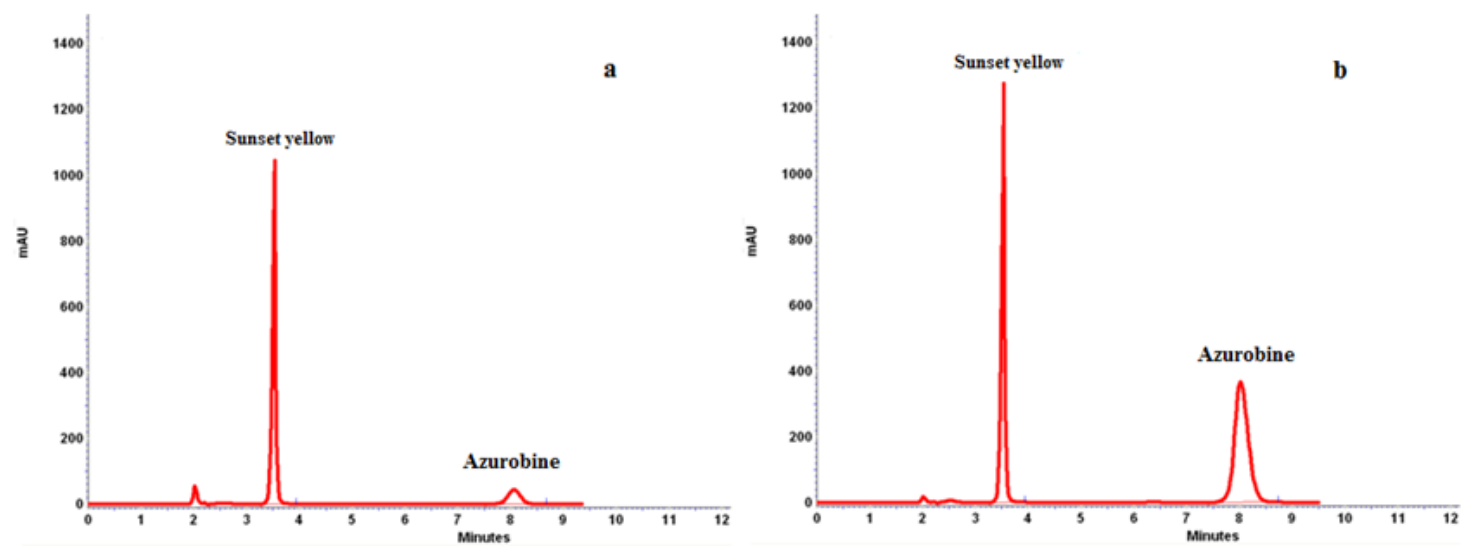

Fig. 3. HPLC-UV-vis chromatogram $(\lambda=500 \mathrm{~nm}$ ) sample of soft drink 15 (a) nonspiked and (b) spike of $10 \mathrm{mg}$ $\mathrm{L}^{-1}$ of mixture standard solution of the two dyes.

\section{Conclusion}

Due to the lack of International Standard Method for the determination of the synthetic dyes in foodstuff, in this research we propose an analytical method for the simultaneous determination of the sunset yellow and azorubine in different soft drink samples. Proposed method is simple, sensitive, rapid, reliable and allows good recoveries of 
the sunset yellow and azorubine in the tested samples. Analysis of the samples showed that some samples only have sunset yellow. In contrast, some companies are used combination of the both sunset yellow and azorubine in their formulation. Moreover, sum of the sunset yellow and azorubine concentration in the tested soft drink sample are in compliance with EU limit $\left(100 \mathrm{mg} \mathrm{L}^{-1}\right)$.

Table 4. Concentration of the food colorants in the samples

\begin{tabular}{|c|c|c|c|c|c|}
\hline Sample ID & $\begin{array}{c}\text { Sunset yellow } \\
\left(\mathrm{mg} \mathrm{Kg}^{-1}\right)\end{array}$ & $\begin{array}{c}\text { Azorubine } \\
\left(\mathrm{mg} \mathrm{Kg}^{-1}\right)\end{array}$ & Sample ID & $\begin{array}{c}\text { Sunset yellow } \\
\left(\mathrm{mg} \mathrm{Kg}^{-1}\right)\end{array}$ & $\begin{array}{c}\text { Azorubine } \\
\left(\mathrm{mg} \mathrm{Kg}^{-1}\right)\end{array}$ \\
\hline Code 1 & 44.7 & $<0.1$ & Code 22 & 29.4 & 1.3 \\
\hline Code 2 & 38.7 & $<0.1$ & Code 23 & 56.9 & $<0.1$ \\
\hline Code 3 & 53.7 & $<0.1$ & Code 24 & 20.6 & 4.4 \\
\hline Code 4 & 42.1 & $<0.1$ & Code 25 & 38.1 & 0.8 \\
\hline Code 5 & 40.0 & $<0.1$ & Code 26 & 27.0 & 1.4 \\
\hline Code 6 & 57.9 & $<0.1$ & Code 27 & 28.7 & 1.0 \\
\hline Code 7 & 43.7 & $<0.1$ & Code 28 & 29.0 & 1.0 \\
\hline Code 8 & 45.8 & $<0.1$ & Code 29 & 25.6 & $<0.1$ \\
\hline Code 9 & 25.4 & 1.0 & Code 30 & 26.9 & 1.7 \\
\hline Code 10 & 26.2 & 1.0 & Code 31 & 60.2 & $<0.1$ \\
\hline Code 11 & 25.1 & 3.1 & Code 32 & 27.6 & 1.5 \\
\hline Code 12 & 26.2 & 2.5 & Code 33 & 24.8 & 1.1 \\
\hline Code 13 & 39.2 & $<0.1$ & Code 34 & 21.2 & 1.3 \\
\hline Code 14 & 40.4 & $<0.1$ & Code 35 & 29.9 & 1.4 \\
\hline Code 15 & 36.7 & $<0.1$ & Code 36 & 24.4 & 0.6 \\
\hline Code 16 & 41.2 & $<0.1$ & Code 37 & 50.8 & $<0.1$ \\
\hline Code 17 & 46.6 & $<0.1$ & Code 38 & 27.6 & 1.9 \\
\hline Code 18 & 25.5 & 1.3 & Code 39 & 21.4 & 1.5 \\
\hline Code 19 & 27.6 & 1.0 & Code 40 & 29.6 & $<0.1$ \\
\hline Code 20 & 28.2 & 1.3 & Code 41 & 38.6 & $<0.1$ \\
\hline Code 21 & 27.0 & 1.2 & Code 42 & 29.0 & 2.3 \\
\hline & \multicolumn{5}{|c|}{ Statistical analysis } \\
\hline & & \multicolumn{2}{|c|}{ Sunset yellow } & \multicolumn{2}{|c|}{ Azorubine } \\
\hline Average & & \multicolumn{2}{|c|}{$34.5\left(\mathrm{mg} \mathrm{Kg}^{-1}\right)$} & \multicolumn{2}{|c|}{$1.55\left(\mathrm{mg} \mathrm{Kg}^{-1}\right)$} \\
\hline Range & & \multicolumn{2}{|c|}{$20.6-60.2\left(\mathrm{mg} \mathrm{Kg}^{-1}\right)$} & \multicolumn{2}{|c|}{$4.4\left(\mathrm{mg} \mathrm{Kg}^{-1}\right)-<0.1$} \\
\hline SD & & \multicolumn{2}{|c|}{$10.8\left(\mathrm{mg} \mathrm{Kg}^{-1}\right)$} & \multicolumn{2}{|c|}{$0.84\left(\mathrm{mg} \mathrm{Kg}^{-1}\right)$} \\
\hline
\end{tabular}

The EU limit is $\left(100 \mathrm{mg} \mathrm{L}^{-1}\right)$

\section{References}

[1]. R.P. Heaney and K. Rafferty, Carbonated beverages and urinary calcium excretion. American Journal of Clinical Nutrition, 74, 2001, 343-347.

[2]. V.S. Malik, M.B. Schulze and F.B. Hu, Intake of sugar-sweetened beverages and weight gain: A systematic review. American Journal of Clinical Nutrition, 84, 2006, 274-278

[3]. G. Wyshak, R.E. Frisch, T.E. Albright, N.L. Albright, I. Schiff and J. Witschi, Nonalcoholic carbonated beverage consumption and bone fractures among women former college athletes. Journal of Orthopaedic Research, 7, 1989, 91-99.

[4]. S.P. Alves, D. Mares Brum, E.C. Branco de Andrade and A.D.P. Netto, Determination of synthetic dyes in selected foodstuffs by high performance liquid chromatography with UV-DAD detection. Food Chemistry, 107, 2008, 489-496.

[5]. N.E. Llamas, M. Garrido, M.S. Di Nezio and B.S. Fernandez, Band Second order advantage in the determination of amaranth, Sunset yellow FCF and Tartrazine by UV-vis and multivariate curve resolution-alternating least squares. Analytica Chimica Acta, $655,2009,38-42$.

[6]. Y.S. Al-Degs, Determination of three dyes in commercial soft drinks using HLA/GO and liquid chromatography. Food Chemistry, 117, 2009, 485-490.

[7]. W. Zhang, T. Liu, X. Zheng, W. Huang and C. Wan, Surface-enhanced oxidation and detection of Sunset yellow and Tartrazine using multi-walled carbon nanotubes film-modified electrode. Colloids and Surface B, 74, 2009, $28-31$.

[8]. R.D. Combes and R.B. Haveland-Smith, A review of the genotoxicity of food, drug and cosmetic colours and other azo, triphenylmethane and xanthene dyes. Mutation Research: Reviews in Genetic Toxicology, 98, 1982, 101-243.

[9]. Directive 94/36//EC on colours for use in foodstuffs (1994). European Parliament and Council.

[10]. H. Oka, Y. Ikai, N. Kawamura, M. Yamada, H. Inoue, T. Ohno, K. Inagaki, A. Kuno and N. Yamamoto, Simple method for the analysis of food dyes on reversed-phase thin-layer plates. Journal of Chromatography, 411, 1987, 437-44.

[11]. Y. Ni, J. Bai and L. Jin, Simultaneous adsorptive voltammetric analysis of mixed colorants by multivariate calibration approach. Analytica Chimica Acta 329, 1996, 65-72.

[12]. S. Combeau, M. Chatelut and O. Vittori, Identification and simultaneous determination of Azorubin, Allura red and Ponceau 4R by differential pulse polarography: application to soft drinks. Talanta, 56, 2002, 115-122.

[13]. J.J.B. Nevado, J.R. Flores, M.J.V. Llerena and N.R. Farinas, Rapid spectrophotometric method to resolve ternary mixtures of Tartrazine, Quinoline Yellow and Patent Blue V in commercial products, Fresenius Journal of Analytical Chemistry, 365, 1999, 383-388

[14]. E.C. Vidotti, J.C. Cancino, C.C. Oliveira and M.D.C.E. Rollemberg, Simultaneous determination of food dyes by first derivative spectrophotometry with sorption onto polyurethane foam. Analytical Science, 21,2005, 149-153.

[15]. H.Y. Huang, Y.C. Shih and Y.C. Chen, Determining eight colorants in milk beverages by capillary electrophoresis, Journal of Chromatography A, 959, 2002, 317-325. 
[16]. M.A. Prado, L.F.V. Boas, M.R. Bronze and H.T. Godoy, Validation of methodology for simultaneous determination of synthetic dyes in alcoholic beverages by capillary electrophoresis. Journal of Chromatography A, 1136, 2006, 231-236.

[17]. Q.C. Chen, S.F. Mou, X.P. Hou, J.M. Riviello and Z.M. Ni, Determination of eight synthetic food colorants in drinks by highperformance ion chromatography, Journal of Chromatography A, 827, 1998, 73-81.

[18]. K. Nakazawa, Y. Shimamura, K. Nakajima, Y. Kikuchi, K. Nakagome and Y. Tamura, Studies on Newer Adulterants and Contaminants. Annual Report of The Tokyo Metropolitan Research Laboratory of Public Health, 46, 1995, 108-114.

[19]. T. Zou, P. He, A. Yasen, Z. Li, Determination of seven synthetic dyes in animal feeds and meat by high performance liquid chromatography with diode array and tandem mass detectors. Food Chemistry, 138, 2013, 1742-1748.

[20]. J. Kirschbaum, C. Krause, S. Pfalzgraf and H. Bruckner, Development and evaluation of an HPLC-DAD method for determination of synthetic food colorants. Chromatographia, 57, 2003, S115-S119.

[21]. M.G. Kiseleva, V.V. Pimenova and K.I. Eller, Determination of Synthetic Dyes in Food. Journal of analytical Chemistry, 58, 2003, 685-690.

[22]. M.S. Garcia-Falcon and J. Simal-Gandara, Determination of food dyes in soft drinks containing natural pigments by liquid chromatography with minimal clean-up. Food Control, 16, 2005, 293-297.

[23]. K.S. Minioti, C.F. Sakellariou and N.S. Thomaidis, Determination of 13 synthetic food colorants in water-soluble foods by reversed-phase high-performance liquid chromatography coupled with diode-array detector, Analytica Chimica Acta, 583, 2007, 103-110.

[24]. N. Yoshioka and K. Ichihashi Determination of 40 synthetic food colors in drinks and candies by high-performance liquid chromatography using a short column with photodiode array detection. Talanta, 74, 2008, 1408-1413. 